\title{
Frequent Eating Out and 10-Year Cardiovascular Disease Risk: Evidence from a Community Observatory in Malaysia
}

\author{
Chiew Way Ang $\left(\mathbb{D},{ }^{1}\right.$ Roshidi Ismail $\left(\mathbb{D},{ }^{1}\right.$ Zaid Kassim, ${ }^{2}$ Ahmad Nizal Mohd Ghazali, \\ Daniel Reidpath $\left(\mathbb{1},{ }^{1,3}\right.$ and Tin Tin Su $\left(\mathbb{C}^{1}\right.$ \\ ${ }^{1}$ South East Asia Community Observatory (SEACO) \& Global Public Health Jeffrey Cheah School of Medicine and Health Sciences, \\ Monash University Malaysia, 47500 Subang Jaya, Selangor, Malaysia \\ ${ }^{2}$ Segamat District Public Health Office, Ministry of Health, 85000 Segamat, Johor, Malaysia \\ ${ }^{3}$ International Centre for Diarrhoeal Disease Research, Bangladesh
}

Correspondence should be addressed to Tin Tin Su; tintin.su@monash.edu

Received 19 October 2021; Accepted 10 February 2022; Published 7 March 2022

Academic Editor: Krzysztof Siemianowicz

Copyright (c) 2022 Chiew Way Ang et al. This is an open access article distributed under the Creative Commons Attribution License, which permits unrestricted use, distribution, and reproduction in any medium, provided the original work is properly cited.

\begin{abstract}
Despite increasing mortality rates from cardiovascular diseases (CVDs) in low- and middle-income countries, information on the estimation of 10-year CVD risk remains to be sparse. Therefore, this study was aimed at predicting the 10-year CVD risk among community dwellers in Malaysia and at identifying the association of distal (socioeconomic characteristics) and proximal (lifestyle practices) factors with 10-year CVD risk. We calculated the 10-year CVD risk score among 11,897 eligible respondents from the community health survey conducted by the South East Asia Community Observatory (SEACO) using the Framingham risk score (FRS). The findings indicate that $28 \%$ of respondents have a high chance of having CVD within the next ten years. After adjusting for the age of respondents, demographic and socioeconomic factors such as gender, ethnicity, marital status, education, income, and occupation had an association with the 10-year CVD risk. In addition, frequent eating out had an association with 10-year CVD risk, while physical activity was found to have no association with predicted CVD risk. CVD remained among the top five mortality causes in Malaysia. Health promotion strategies should emphasize the importance of having home-cooked meals as a healthy dietary behavior, to reduce the mortality rate among Malaysians due to CVDs.
\end{abstract}

\section{Introduction}

Cardiovascular diseases (CVDs) account for the majority of noncommunicable disease (NCD) deaths across the globe [1]. NCDs contributed to about $73 \%$ of the total deaths in Malaysia, with the largest contributor being CVDs (35\%) in 2015 [2]. Ischaemic heart disease remained among the five principal causes of deaths in Malaysia (15.6\%) in 2019 [3].

In addition, the prevalence of obesity (17.7\%), hypercholesterolemia (47.7\%), and diabetes (17.5\%) had increased among Malaysian adults [4]. Since individuals may have one or more CVD risk factors and/or chronic disease conditions, the progression of a particular CVD risk factor cannot accurately predict future CVD risk at the population level. The Framingham risk scoring (FRS) model can predict the CVD outcomes "fairly well" in the Asian population [5-9]. However, there remain to be limited findings on the 10-year CVD risk predicted by using a representative population sample in Asian countries with developing economies such as Malaysia.

In the related literature, the association between behavioural or lifestyle exposure such as unhealthy diets and physical inactivity with individual CVD risk factors such as obesity [10-12], hypertension [13, 14], diabetes [11], and hyperlipidaemia $[14,15]$ has been documented. However, past studies investigating the relationship between lifestyle factors such as diet and physical activity with 10-year CVD risk are lacking. Hence, this study was aimed at predicting the 10year CVD risk among Malaysians and at identifying the association of distal (socioeconomic characteristics) and proximal factors (lifestyle practices) with a 10-year CVD risk. 


\section{Materials and Methods}

2.1. Study Design and Data Collection. This study utilized data from the community health survey 2013 collected by the South East Asia Community Observatory (SEACO). SEACO is a health and demographic surveillance system (HDSS) established in Segamat, Johor, Malaysia [16]. This surveillance site covers approximately 44,900 individuals that reside in 13,400 households in the baseline enumeration (household census) conducted in 2012 [16]. SEACO conducted house-to-house interviews to obtain the demographic and socioeconomic status (e.g., education, age, ethnicity, and income) and self-reported information on lifestyle practice and dietary behaviour (e.g., smoking, physical activity, and frequency of eating outside). Anthropometric measurements (e.g., height, weight, blood pressure, and random blood glucose) were also conducted as part of the home-based health screening among respondents aged 35 years and above. Data collection was undertaken from August 2013 to July 2014. The total number of respondents in this survey was 25,184 [16].

2.2. Selection of Respondents. The respondents with no history of CVD were eligible for this FRS prediction model. From among 25,184 respondents, only 13,804 had blood pressure measurement. In addition, we considered the exclusion of the respondents that answered "Yes" to the following questions: (1) "Have you ever been told by a doctor/ medical assistant that you have heart disease?" or (2) "Have you ever been told by a doctor/medical assistant that you have had a stroke?". However, the number of respondents was further reduced to 11,897 because of missing information (Figure 1). We included all eligible participants in our data analysis.

2.3. Cardiovascular (CVD) Risk Score. The outcome variable was modified FRS point proposed by D'Agostino et.al [17] to determine the 10-year CVD risk. To estimate the 10-year CVD risk score, the researchers utilized nonlaboratory predictors: age (in years), body mass index (BMI), antihypertension medication use, systolic blood pressure (SBP), smoking status, and diabetes mellitus status. Respondents were classified as smokers if they reported "currently smoking." Anthropometric measurements such as height $(\mathrm{cm})$ and weight $(\mathrm{kg})$ were obtained through home-based screening during interviews. Body mass index (BMI) was calculated by dividing the weight with height in metres squared. Three blood pressure (BP) readings were taken using the Omron HEM 7120 E Blood Pressure Monitor M2 Basic Digital Intellisense following the standard STEPwise guideline [18]. However, only the second and third BP readings were averaged and used in the data analysis, as the first reading may overestimate the mean BP [19].

The classic FRS was previously validated in Malaysia by $\mathrm{Ng}$ and Chia [20]. Meanwhile, Su et.al [9] predicted and compared the 10-year CVD risk among low-income urban dwellers in Metropolitan Kuala Lumpur using both classic and modified FRS, in which both models reported similar findings. We followed the steps proposed by D'Agostino et.al

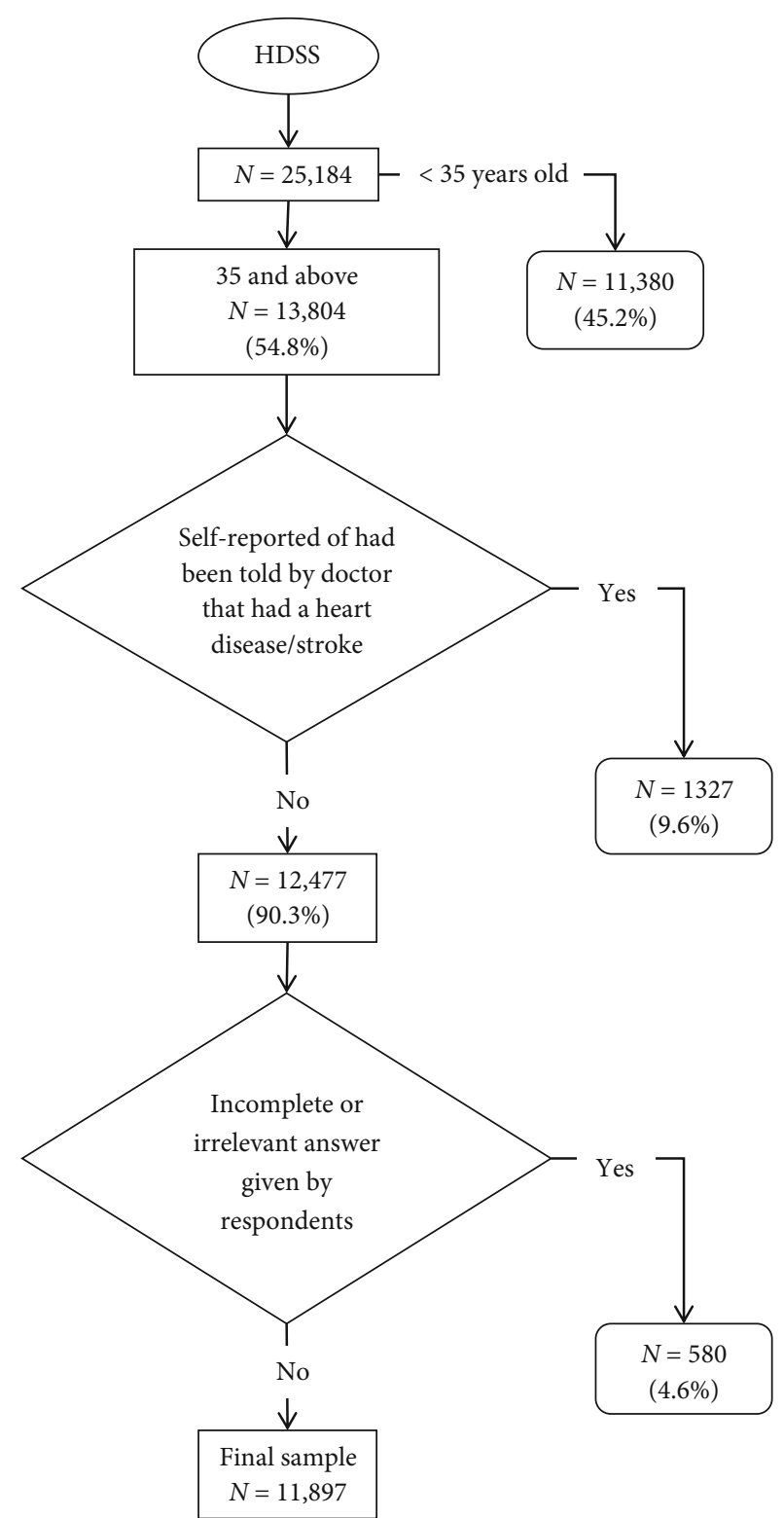

FIgURE 1: Study sample.

in the prediction of the CVD risk. First, the FRS point from each category was identified and summed up. Then, the total FRS points obtained were converted into 10-year CVD risk, classified as low $(\leq 6 \%)$, moderate (7 to $20 \%$ ), and high $(>20 \%)[9,17]$.

2.4. Demographic and Socioeconomic of Respondents. The demographic variables included were age, gender, ethnicity (Malay; Chinese; Indian; Aborigine; and others), and marital status (never married; married; separated/divorced; widowed/widower; and others). Socioeconomic variables included were income (below RM 1000; RM1000-RM1999; RM2000-RM2999; and RM3000 and above), highest education level attained (no formal education; primary; secondary; tertiary; and other [e.g., religious school and international school]), and occupation (paid employee; self-employed; homemaker; not working; pensioner; and other). The 
education status of the respondents was also used as the proxy of the level of health literacy $[21,22]$.

2.5. Dietary and Lifestyle Practice. Lifestyle practice included frequency of eating out and level of total physical activity. Frequency of meals eaten outside acted as a proxy for healthy eating habit $[23,24]$. The level and intensity of physical activity were measured by the validated Malay version of the Global Physical Activity Questionnaire (GPAQ) by WHO [25]. The categorisation of the level of total physical activity was low, moderate, and high according to the GPAQ guideline [25].

2.6. Statistical Analysis. Data were analysed using IBM SPSS version 24. Descriptive statistics presented the characteristics of the respondents and variables used in deriving FRS scores. Chi-square tests were conducted to examine the association between 10-year CVD risks with the selected independent variables. Multiple linear regression outlined the association between the 10-year CVD point scores with the demographic and socioeconomic variables and lifestyle behaviour.

2.7. Ethics Approval. The study was approved by the Monash University Human Research Ethics Committee (MUHREC) (Project ID: 13142). The respondents were given an explanatory sheet and a consent form by the data collectors (DCs) from SEACO during the face-to-face interviews. The DCs conducted the interviews and performed home-based screening after the respondents agreed and signed the consent form.

\section{Results}

A total of 11,897 respondents without a history of CVDs were included in this study. Table 1 presents the demographic, socioeconomic, and dietary and lifestyle practice data of the respondents. About $35 \%$ of the respondents were aged 60 and above. Approximately 57\% were female. The majority of the respondents were Malay (63.4\%), follow by Chinese $(25.1 \%)$ and Indian (9.6\%). Most of the respondents $(88.6 \%)$ had at least primary or secondary education. About $53 \%$ of the respondents earned below RM1000 on a monthly basis. The majority of the respondents $(76 \%)$ reported a frequency of eating out of less than 6 meals per week, while about $90 \%$ of respondents had a low level of total physical activity.

Table 2 summarises the characteristics of the variables used for constructing the FRS model. The majority of the respondents $(87.3 \%)$ reported that they did not take antihypertensive medication. About $86 \%$ were nonsmokers, and about $90 \%$ were nondiabetic patients. The mean age was about 55 years old, and the average of the SBP reading was $132.6 \mathrm{~mm} / \mathrm{Hg}$. The mean BMI among the respondents was $26.6 \mathrm{~kg} / \mathrm{m}^{2}$. The mean predicted CVD risk was $11.29(95 \%$ CI, 11.19 to 11.39 ).

Table 3 summarises the demographic, socioeconomic, and dietary and lifestyle practice by CVD risk. The results indicate that about $28 \%$ and $43 \%$ of the respondents were at high and moderate risks of CVD, respectively. Compared to other age groups, respondents aged 70 and above had a
TABle 1: Demographic, socioeconomic, and dietary and lifestyle practice of respondents $(N=12,477)$.

\begin{tabular}{|c|c|c|}
\hline Variable & $n$ & $\%$ \\
\hline \multicolumn{3}{|l|}{ Age groups } \\
\hline 35 to 39 & 1,249 & 10.0 \\
\hline 40 to 49 & 3,036 & 24.3 \\
\hline 50 to 59 & 3,871 & 31.0 \\
\hline 60 to 69 & 2,717 & 21.8 \\
\hline 70 and above & 1,604 & 12.9 \\
\hline \multicolumn{3}{|l|}{ Gender } \\
\hline Male & 5,425 & 43.5 \\
\hline Female & 7,052 & 56.5 \\
\hline \multicolumn{3}{|l|}{ Race } \\
\hline Malay & 7,916 & 63.4 \\
\hline Chinese & 3,129 & 25.1 \\
\hline Indian & 1,197 & 9.6 \\
\hline Aborigine & 136 & 1.1 \\
\hline Other & 99 & 0.8 \\
\hline \multicolumn{3}{|l|}{ Marital status } \\
\hline Never married & 561 & 4.5 \\
\hline Married & 10,129 & 81.4 \\
\hline Separated/divorced & 249 & 2.0 \\
\hline Widowed/widower & 1,460 & 11.7 \\
\hline Other & 78 & 0.4 \\
\hline \multicolumn{3}{|l|}{ Education } \\
\hline No formal education & 413 & 3.4 \\
\hline Primary/secondary & 10,827 & 88.6 \\
\hline Tertiary & 570 & 4.7 \\
\hline Other & 407 & 3.3 \\
\hline \multicolumn{3}{|l|}{ Monthly income ${ }^{\dagger}$} \\
\hline Below RM1000 & 6,548 & 52.5 \\
\hline RM1000-RM1999 & 3,357 & 26.9 \\
\hline RM2000-RM2999 & 1,370 & 11.0 \\
\hline RM3000 and above & 1,202 & 9.6 \\
\hline \multicolumn{3}{|l|}{ Occupation } \\
\hline Paid employee & 3,487 & 27.9 \\
\hline Self-employed & 2,277 & 18.2 \\
\hline Homemaker & 4,299 & 34.5 \\
\hline Not working & 1,487 & 11.9 \\
\hline Pensioners & 883 & 7.1 \\
\hline Other & 53 & 0.4 \\
\hline \multicolumn{3}{|c|}{ Frequency of meals taken outside per week } \\
\hline 0 meal & 4,400 & 35.3 \\
\hline $1-5$ meals & 5,070 & 40.7 \\
\hline $6-10$ meals & 1,428 & 11.5 \\
\hline 11 meals and above & 1,558 & 12.5 \\
\hline \multicolumn{3}{|c|}{ Level of total physical activity } \\
\hline Low & 11,121 & 89.1 \\
\hline Moderate & 649 & 5.2 \\
\hline High & 707 & 5.7 \\
\hline
\end{tabular}

Notes: ${ }^{\dagger}$ USD \$1 is equivalent to RM3.00 (13 May 2013). 
TABLE 2: Characteristics of variable in FRS model $(N=12,477)$.

\begin{tabular}{|c|c|c|c|c|}
\hline Variable & \multicolumn{2}{|c|}{$n$} & \multicolumn{2}{|c|}{$\%$} \\
\hline \multicolumn{5}{|c|}{ On antihypertensive meds } \\
\hline No & \multicolumn{2}{|c|}{10,893} & \multicolumn{2}{|c|}{87.3} \\
\hline Yes & \multicolumn{2}{|c|}{1,583} & \multicolumn{2}{|c|}{12.7} \\
\hline \multicolumn{5}{|l|}{ Smoking status } \\
\hline No & \multicolumn{2}{|c|}{10,620} & \multicolumn{2}{|c|}{85.7} \\
\hline Yes & \multicolumn{2}{|c|}{1,773} & \multicolumn{2}{|c|}{14.3} \\
\hline \multicolumn{5}{|l|}{ Diabetes status } \\
\hline No & \multicolumn{2}{|c|}{11,183} & \multicolumn{2}{|c|}{89.6} \\
\hline \multirow[t]{2}{*}{ Yes } & \multicolumn{2}{|c|}{1,294} & \multicolumn{2}{|c|}{10.4} \\
\hline & Mean & S.D. & Min & Max \\
\hline Age (years) & 55.2 & 11.8 & 35.0 & 98.0 \\
\hline Systolic BP & 132.6 & 19.8 & 56.0 & 269.5 \\
\hline BMI & 26.6 & 5.3 & 7.4 & 66.2 \\
\hline FRS points & 11.3 & 5.6 & -1.0 & 29.0 \\
\hline CVD risk (\%) & 13.7 & 9.8 & 1.0 & 30.0 \\
\hline
\end{tabular}

higher risk of getting CVD. Male respondents had a high CVD risk. Malay, Chinese, and Aborigine respondents had a high CVD risk compared to the Indian ethnicity. Respondents who were widowed/widower, without formal education, or earned RM1,000-RM1,999 monthly were predicted to have a high CVD risk. The results also show that the risk of getting CVD was quite evenly distributed across all categories for frequency of eating outside per week and level of total physical activity.

Table 4 presents the association between 10-year CVD risk and demographic, socioeconomic, and dietary and lifestyle practice, adjusted for age. This study was aimed at identifying the impact of lifestyle practices with CVD risk prediction among a semirural population; hence, the presentation of two independent models are as follows. Model 1 comprised CVD risk and demographic and socioeconomic variables; while model 2 comprised model 1 in addition to physical activity and dietary practice. By presenting the two models, this study distinguishes the effect of demographic and socioeconomic status and lifestyle practices on CVD risk prediction among the respondents. In model 1, female respondents had lower 10-year CVD risk points $(b=1.456,95 \% \mathrm{CI},-1.636$ to -1.277$)$ as compared to males. Chinese ( $b=-0.765,95 \% \mathrm{CI},-0.918$ to -0.613$)$ and Indian $(b=-0.251,95 \% \mathrm{CI},-0.471$ to -0.031$)$ respondents had lower 10-year CVD risk points as compared to Malay respondents, while the Aborigine group $(b=1.797,95 \% \mathrm{CI}$, 1.183 to 2.410 ) had higher CVD risk points compared to Malay respondents. Only respondents that were widowed/ widower had higher CVD risk as compared to never married respondents ( $b=0.831,95 \% \mathrm{CI}, 0.456$ to 1.207$)$. Respondents that studied primary/secondary level $(b=-0.875$, $95 \% \mathrm{CI},-1.249$ to -0.501$)$, tertiary level $(b=-1.088,95 \%$ CI, -1.572 to -0.603$)$, and other types of schools $(b=-0.714,95 \%$ CI, -1.220 to -0.207$)$ had a lower CVD risk as compared to those who had no formal education. Respondents who earned more than RM1,000 monthly had a lower
CVD risk as compared to those who earned less than RM1,000 per month. In terms of occupation status, the CVD risk points were higher among the self-employed ( $b=0.218,95 \%$ CI, 0.017 to 0.418$)$, homemakers ( $b=0.459$ , 95\% CI, -0.245 to 0.672$)$, those who reported not working ( $b=0.757,95 \% \mathrm{CI}, 0.499$ to 1.016 ), and other unspecified occupations $(b=0.455,95 \% \mathrm{CI}, 0.169$ to 0.742$)$, as compared to paid employees.

In model 2, those who reported eating solely at home $(b=-0.342,95 \%$ CI, -0.560 to -0.124$)$ or eating out less frequently ( 1 to 5 meals per week) ( $b=-0.574,95 \%$ CI, -0.781 to -0.367$)$ had lower predicted CVD risk points as compared to those who ate out 11 times or more per week. There was no association between physical activities with CVD risk prediction. The findings on distal factors are similar to model 1 .

\section{Discussion}

The prevalence of predicted CVD risk among the respondents was $28.9 \%, 42.9 \%$, and $28.2 \%$ for low, moderate, and high CVD risk, respectively. The prevalence of CVD risk was lower as compared to a study done in Kuala Langat (a semirural area) in 1993 , wherein $55.8 \%$ of males and $15.1 \%$ of females reported to have a high CVD risk [6]. In contrast, our study shows that $47.2 \%$ of males and $13.6 \%$ of females had a high CVD risk. However, the prevalence of CVD risk in our study was higher as compared to other past studies in the context of Malaysia. Su et. al. [9] reported that there were $21.8 \%$ and $38.9 \%$ of respondents who had a high and moderate CVD risk, respectively, among urban dwellers in Kuala Lumpur in 2012. The Prospective Urban Rural Epidemiology (PURE) project conducted in 2008 reported that the prevalence of high CVD risk was only $16 \%$ [11]. Ahmad et. al. [26] utilized the NHMS data from 2006 until 2015 to determine the prevalence of CVD risk among Malaysians by using the WHO/ISH risk prediction chart. The authors discovered that the prevalence of high CVD risk $(>40 \%)$ increased among female respondents aged 70 to 79 with time (11.1\% in 2006 to $15.3 \%$ in 2015) [26].

The current study shows that there was an association between demographic, socioeconomic, and dietary and lifestyle practice with CVD risk. Older respondents had a higher CVD risk, which is an inevitable event as a process of ageing [26-28]. Older individuals encountered more health issues and sickness such as hypertension [28] and diabetes [27], which are CVD risk factors. Male respondents were found to have a higher CVD risk compared to females. This finding is consistent with the past studies conducted in Malaysia [5, 6, 9]. Meanwhile, Malay, Chinese, and Aborigine respondents had a higher CVD risk compared to the Indian ethnicity. This finding is contrary to the previous studies in Malaysia, where only Malays had a higher predicted CVD risk as compared to other ethnic groups $[5,9]$. Meanwhile, Amiri et al. [27] discovered that Indians had a lower risk of having more than one CVD risk factor, while another study showed that Indian males aged 45 and above had higher odds of having more than three CVD risk factors due to dietary and lifestyle practices as well as genetic factors 
TABLe 3: Demographic, socioeconomic, and dietary and lifestyle practice by CVD risk $(N=11,897)$.

\begin{tabular}{|c|c|c|c|c|c|c|}
\hline \multirow[t]{2}{*}{ Variables } & \multicolumn{2}{|c|}{$\begin{array}{c}\text { Low } \\
(n=3,439)\end{array}$} & \multicolumn{2}{|c|}{$\begin{array}{c}\text { CVD risk } \\
\text { Moderate } \\
(n=5,099)\end{array}$} & \multicolumn{2}{|c|}{$\begin{array}{c}\text { High } \\
(n=3,359)\end{array}$} \\
\hline & $n$ & $\%$ & $n$ & $\%$ & $n$ & $\%$ \\
\hline Age groups & \multicolumn{6}{|c|}{$\chi^{2}=5903.081 * * *$} \\
\hline 35 to 39 & 1,035 & 87.5 & 170 & 14.1 & 2 & 0.2 \\
\hline 40 to 49 & 1,557 & 52.9 & 1,225 & 41.6 & 163 & 5.5 \\
\hline 50 to 59 & 703 & 18.9 & 2,194 & 58.9 & 828 & 22.2 \\
\hline 60 to 69 & 144 & 5.6 & 1,116 & 43.1 & 1,331 & 51.4 \\
\hline 70 and above & 0 & 0.0 & 394 & 27.6 & 1,035 & 72.4 \\
\hline Gender & \multicolumn{6}{|c|}{$\chi^{2}=2222.545 * * *$} \\
\hline Male & 551 & 10.6 & 2,184 & 42.2 & 2,442 & 47.2 \\
\hline Female & 2,888 & 43.0 & 2,915 & 43.4 & 917 & 13.6 \\
\hline Ethnicity & \multicolumn{6}{|c|}{$\chi^{2}=64.773 * * *$} \\
\hline Malay & 2,131 & 28.4 & 3,252 & 43.3 & 2,123 & 28.3 \\
\hline Chinese & 804 & 26.8 & 1,298 & 43.2 & 900 & 30.0 \\
\hline Indian & 425 & 36.6 & 456 & 39.2 & 281 & 24.2 \\
\hline Aborigine & 33 & 24.6 & 60 & 44.8 & 41 & 30.6 \\
\hline Other & 46 & 49.5 & 33 & 35.5 & 14 & 15.1 \\
\hline Marital status & \multicolumn{6}{|c|}{$\chi^{2}=344.095 * * *$} \\
\hline Never married & 220 & 40.9 & 230 & 42.8 & 88 & 16.4 \\
\hline Married & 2,932 & 30.4 & 4,122 & 42.4 & 2,667 & 27.4 \\
\hline Separated/divorced & 100 & 41.8 & 106 & 44.4 & 33 & 13.8 \\
\hline Widowed/widower & 150 & 11.3 & 619 & 46.5 & 561 & 42.2 \\
\hline Other & 23 & 52.3 & 14 & 31.8 & 7 & 15.9 \\
\hline Education & \multicolumn{6}{|c|}{$\chi^{2}=168.535 * * *$} \\
\hline No formal education & 45 & 12.2 & 158 & 42.7 & 167 & 45.1 \\
\hline Primary/secondary & 3,044 & 29.3 & 4,442 & 42.8 & 2,903 & 27.9 \\
\hline Tertiary & 239 & 43.6 & 213 & 38.9 & 96 & 17.5 \\
\hline Other & 60 & 16.3 & 176 & 48.0 & 131 & 35.7 \\
\hline Monthly income ${ }^{\dagger}$ & \multicolumn{6}{|c|}{$\chi^{2}=107.428 * * *$} \\
\hline Below RM1,000 & 1,907 & 30.9 & 2,638 & 42.8 & 1,618 & 26.3 \\
\hline RM1,000-RM1,999 & 774 & 23.9 & 1,342 & 41.5 & 1,117 & 34.5 \\
\hline RM2,000-RM2,999 & 401 & 30.1 & 583 & 43.8 & 348 & 26.1 \\
\hline RM3,000 and above & 357 & 30.5 & 536 & 45.9 & 276 & 23.6 \\
\hline Occupation & \multicolumn{6}{|c|}{$\chi^{2}=1978.565 * * *$} \\
\hline Paid employee & 1,200 & 35.5 & 1,546 & 45.8 & 630 & 18.7 \\
\hline Self-employed & 362 & 16.5 & 875 & 40.0 & 952 & 43.5 \\
\hline Homemaker & 1,675 & 40.5 & 1,917 & 46.3 & 547 & 13.2 \\
\hline Not working & 166 & 12.4 & 488 & 36.5 & 682 & 51.0 \\
\hline Others & 36 & 4.2 & 273 & 31.9 & 548 & 63.9 \\
\hline Frequency of meals taken outside per week & \multicolumn{6}{|c|}{$\chi^{2}=13.028 *$} \\
\hline 0 meal & 1,149 & 28.1 & 1,731 & 42.4 & 1,207 & 29.5 \\
\hline $1-5$ meals & 1,473 & 30.0 & 2,126 & 43.4 & 1,304 & 26.6 \\
\hline $6-10$ meals & 391 & 28.6 & 574 & 42.1 & 400 & 29.3 \\
\hline 11 meals and above & 419 & 27.5 & 661 & 43.4 & 443 & 29.1 \\
\hline Level of total physical activity & \multicolumn{6}{|c|}{$\chi^{2}=11.576 *$} \\
\hline Low & 3,086 & 29.2 & 4,532 & 42.8 & 2,962 & 28.0 \\
\hline Moderate & 181 & 28.8 & 246 & 39.2 & 201 & 32.0 \\
\hline High & 172 & 25.0 & 321 & 46.6 & 196 & 28.4 \\
\hline
\end{tabular}

Notes: ${ }^{\dagger}$ USD $\$ 1$ is equivalent to RM3.00 (13 May 2013). 
TABLE 4: Regression analysis of Framingham point scores $(N=11,897)$.

\begin{tabular}{|c|c|c|c|c|}
\hline Variables & $\begin{array}{c}\text { Model 1 } \\
\text { Regression coefficient (95\% CI) }\end{array}$ & S.E. & $\begin{array}{c}\text { Model 2 } \\
\text { Regression coefficient (95\% CI) }\end{array}$ & S.E. \\
\hline \multicolumn{5}{|l|}{ Gender } \\
\hline Male & REF & & REF & \\
\hline Female & $-1.456(-1.636,-1.277)^{* * *}$ & 0.092 & $-1.442(-1.622,-1.263)^{* * *}$ & 0.092 \\
\hline \multicolumn{5}{|l|}{ Ethnicity } \\
\hline Malay & REF & & REF & \\
\hline Chinese & $-0.765(-0.918,-0.613)^{* * *}$ & 0.078 & $-0.859(-1.015,-0.702)^{* * *}$ & 0.080 \\
\hline Indian & $-0.251(-0.471,-0.031)^{*}$ & 0.112 & $-0.245(-0.466,-0.025)^{*}$ & 0.113 \\
\hline Aborigine & $1.797(1.183,2.410)^{* * *}$ & 0.313 & $1.696(1.077,2.315)^{* * *}$ & 0.316 \\
\hline Others & $-0.042(-0.460,0.677)$ & 0.367 & $-0.118(-0.836,0.600)$ & 0.366 \\
\hline \multicolumn{5}{|l|}{ Marital status } \\
\hline Never married & REF & & REF & \\
\hline Married & $0.191(-0.120,0.501)$ & 0.159 & $0.230(-0.082,0.541)$ & 0.159 \\
\hline Separated/divorced & $-0.035(-0.574,0.503)$ & 0.275 & $0.001(-0.537,0.539)$ & 0.274 \\
\hline Widowed/widower & $0.831(0.456,1.207)^{* * *}$ & 0.192 & $0.849(0.473,1.224)^{* * *}$ & 0.191 \\
\hline Others & $-0.725(-1.796,0.346)$ & 0.546 & $-0.606(-1.677,0.464)$ & 0.546 \\
\hline \multicolumn{5}{|l|}{ Education } \\
\hline No formal education & REF & & REF & \\
\hline Primary/secondary & $-0.875(-1.249,-0.501)^{* * *}$ & 0.191 & $-0.844(-1.219,-0.469)^{* * *}$ & 0.191 \\
\hline Tertiary & $-1.088(-1.572,-0.603)^{* * *}$ & 0.247 & $-1.012(-1.497,-0.527)^{* * *}$ & 0.247 \\
\hline Others & $-0.714(-1.220,-0.207)^{* *}$ & 0.258 & $-0.661(-1.167,-0.155)^{*}$ & 0.258 \\
\hline \multicolumn{5}{|l|}{ Monthly income ${ }^{\dagger}$} \\
\hline Below RM1000 & REF & & REF & \\
\hline RM1000-RM1999 & $-0.294(-0.458,-0.130)^{* * *}$ & 0.084 & $-0.322(-0.487,-0.157)^{* * *}$ & 0.084 \\
\hline RM2000-RM2999 & $-0.615(-0.841,-0.389)^{* * *}$ & 0.115 & $-0.664(-0.892,-0.436)^{* * *}$ & 0.116 \\
\hline RM3000 and above & $-0.695(-0.941,-0.450)^{* * *}$ & 0.125 & $-0.796(-1.047,-0.544)^{* * *}$ & 0.128 \\
\hline \multicolumn{5}{|l|}{ Occupation } \\
\hline Paid employee & REF & & REF & \\
\hline Self-employed & $0.218(0.017,0.418)^{*}$ & 0.102 & $0.245(0.044,0.446)^{*}$ & 0.103 \\
\hline Homemaker & $0.459(0.245,0.672)^{* * *}$ & 0.109 & $0.479(0.265,0.692)^{* * *}$ & 0.109 \\
\hline Not working & $0.757(0.499,1.016)^{* * *}$ & 0.132 & $0.790(0.532,1.048)^{* * *}$ & 0.132 \\
\hline Others & $0.455(0.169,0.742)^{* *}$ & 0.146 & $0.472(0.186,0.759)^{* *}$ & 0.146 \\
\hline \multicolumn{5}{|c|}{ Frequency of meals taken outside per week } \\
\hline 11 meals and above & & & REF & \\
\hline $6-10$ meals & & & $-0.176(-0.435,0.083)$ & 0.132 \\
\hline $1-5$ meals & & & $-0.574(-0.781,0.367)^{* * *}$ & 0.105 \\
\hline 0 meal & & & $-0.342(-0.560,-0.124)^{* *}$ & 0.111 \\
\hline \multicolumn{5}{|c|}{ Level of total physical activity } \\
\hline High & & & REF & \\
\hline Moderate & & & $0.017(-0.361,0.396)$ & 0.193 \\
\hline Low & & & $-0.272(-0.547,0.003)$ & 0.140 \\
\hline Constant & $4.595(4.070,5.121)^{* * *}$ & 0.268 & $5.167(4.559,5.775)^{* * *}$ & 0.310 \\
\hline Observations & 11,653 & & 11,637 & \\
\hline Adjusted $R$-squared & 0.614 & & 0.616 & \\
\hline
\end{tabular}

Notes: Abbreviation: Reference: REF; $t$-test significance: ${ }^{* * *} p<0.001,{ }^{* *} p<0.01$, and ${ }^{*} p<0.05$; values in parentheses are $95 \%$ confidence intervals; ${ }^{\dagger} \mathrm{USD} \$ 1$ is equivalent to RM3.00 (13 May 2013). 
[14]. Moreover, respondents who were widowed/widower were reported to have a higher CVD risk. The findings was consistent with the previous study done in Kuala Lumpur, where married individuals and widows/widowers had a higher CVD risk [9].

In this study, respondents without a formal education had a higher prevalence of CVD risks. Previous studies have shown that low education attainment is one of the contributing factors to CVD risk factors [11, 14]. Individuals with lower education attainment tend to have a lower monthly income [29]. Therefore, respondents who earned RM1,000-RM1,999 monthly in this study had higher prevalence of CVD risk. This is because individuals with a low monthly income will have limited access to health services and encounter a financial burden in obtaining medical support [29]. Subsequently, they tend to lower their own concerns and perceptions on their health conditions [29]. In our study, respondents who were not working or worked as other unspecified occupation had a higher CVD risk. This finding is contrary to that by Amiri et al. [27], where paid employees had a higher CVD risk. Another study in Malaysia found that homemakers had a higher prevalence of CVD risk, attributable to unhealthy lifestyles and dietary practices [14].

The novel finding in our study is the inclusion of Aborigines in the prediction of 10-year CVD risk. They were found to have a higher CVD risk. Previous studies on 10year CVD risk among Malaysians mainly focused on major ethnic groups such as Malay, Chinese, and Indian [5, 9, 11], and information on Aborigines and minority communities were often excluded in the research evidence reported. Hence, we would like to highly recommend inclusive NCD health policies and strategies by taking into consideration minority communities and Aborigine groups.

Education attainment of respondents is highly associated with the CVD risk. For instance, respondents with a higher education level (tertiary) had a lower CVD risk as compared to those who had no formal education. This result is consistent with some prior studies $[5,11,30]$, who report that those with a lower education level had a higher predicted CVD risk. Individuals with a lower education level had a poorer understanding of health information, or they had a lower health literacy in general [14]. Individual's health behaviour could be affected by their health literacy [21]. Individuals with higher education attainment had a higher level of health literacy, where some information and knowledge on health required the need of an individual to read and understand the content [21]. In addition, some past studies proved that health literacy served as a mediator or pathway by which education affects health $[21,22]$.

In our study, individuals with a higher income (RM1,000 and above) had a lower predicted CVD risk. A low income will limit the individual access to health services. Therefore, the individual's health condition is often neglected [29]. Our finding shows that respondents that worked jobs other than paid employees had a higher CVD risk, which in line with the study by $\mathrm{Su}$ et. al [9]. This might be due to paid employees having a stable source of income and insurance coverage that can enhance the access for health services and thus reduce the prevalence of CVD risks [9]. It is noteworthy that individuals with a lower educational attainment had a lower source of income, resulting to limited access to healthcare services [29]. Hence, the predicted CVD risk was high among those with a low education level, those with unstable jobs or unemployed, and those with a low income.

Many studies emphasized the importance of physical activity [31-33] and nutrition intake [34,35] in CVD prevention and risk reduction. Our study shows that there is no significant association between physical activity and CVD risk, similar to the study by Yang et al. [36]. However, the finding was contrary to the study done by R. Yadav et. al [37], where two week of a yoga-based lifestyle intervention can reduce the predicted CVD risk score by $11 \%$. Meanwhile, a previous study on civil servants in South-Western Nigeria using the WHO prediction chart showed that those who were physically inactive had a 2.4 times higher risk in developing CVD as compared to those who were physically active [38]. Another study in Korea found that young Korean women (below 40 years old) had a high predicted CVD risk due to an unhealthy lifestyle such as smoking, obesity, or sedentary activity [39]. However, the occurrence of CVD is not only influenced by physical activity; socioeconomic status and dietary habits also play an important role in preventing CVD risk. Hence, the insignificant association of physical activity on 10-year CVD risk in our study does not imply that physical activity is not an important aspect in preventing CVD. Since our data focused on reported physical activity, objective measurements of physical activity should be included in future data collection, and this would provide more robust information.

Respondents who reported eating solely at home or eating out less often (less than 6 meals per week) had a lower CVD risk. This might be due to the food choices practised by Malaysians [40]. According to the Household Expenditure Survey Report 2019, people who reside in rural areas use about a quarter of their income on raw foods and ingredients, while those who live in urban areas only spend $16 \%$ of their income on similar products [41]. This indicates that people in rural areas have a higher tendency to eat homecooked food, which is consistent with the findings of this study. The report found that the foods and goods that were most purchased included rice, chicken, eggs, vegetables, fish, beef, and fruits that are essential and nutritious for the body [41]. Many past studies have proven that diets with a low sugar intake help to prevent CVD [34, 42]. Refined carbohydrates (e.g., white rice and white flour), sweetened beverages, high sodium intake, and saturated fats increased CVD risk [34, 43]. In Malaysia, easily accessible fast food outlets [44] and habit of frequently eating out resulted in an increased trend of consuming unhealthy fast foods which are energy dense and high in fat and high in sodium content [45-47]. Meanwhile, people who eat out tend to choose popular food that is high in fats and sodium such as nasi lemak (rice cooked with coconut milk), pasta, chicken rice, and rice with thick and rich gravies. This food choice could increase the CVD risk among those who frequently eat outside. A past study done in Malaysia also concluded that incorrect and disordered eating patterns among Malaysians was associated 
with the occurrence of obesity, which was one of the risk factors of CVD [48].

This study found that education played an important role in reducing CVD risk. By improving their socioeconomic status through education [29], people are also able to gain knowledge and understand the concept of healthy eating [14]. Therefore, health education should be introduced through formal and informal curricula. Besides that, encouraging home-cooked meals should be a key message for health promotion. This is also in line with the National Plan of Action for Nutrition of Malaysia III 2016-2025 (NPANM III), where the government emphasized promoting healthy eating and active living [4]. Various strategies such as promoting nutrition activities via mass media and conducing advocacy and awareness on Malaysian Healthy Plate concepts through various activities (campaigns, talks, exhibitions, etc.) were implemented in promoting healthy eating [4]. However, these activities are more focused on urban areas. Healthy eating information and education for the rural population should be considered as a priority area for NCD prevention and control. Apart from the Internet, the government should spread health information through broadcasting, newspapers, campaigns, and other offline outlets. This is because older people face difficulty in finding information online, and this causes a low level of health literacy among elderly [49]. Increasing the level of health literacy among older adults is essential, as they are exposed to more health risks and limited access to digital health information [50]. Besides that, financial aid support for low-income groups should be implemented to reduce the financial burden for seeking medical help among the poor. For instance, "Skim Peduli Kesihatan for the bottom 40\% income group" (Healthcare Scheme B40 or PeKa B40) was founded as about $48 \%$ of the B40 group aged 40 and above had at least one NCD that was often undiagnosed [51].

The strength of this study is the large population representative sample that consisted of the major and minor ethnic groups in the country. This study reported cumulative CVD risk in 10-year prediction, which is a more pragmatic approach than measuring individual risk factors. However, there are some limitations inherent in this study. The use of a self-reported assessment may lead to measurement and recall bias, where the respondents might underreport or overreport the lifestyle practices, particularly the level of physical activity.

\section{Conclusions}

In summary, there is an association between demographic, socioeconomic, and dietary practice with 10-year CVD risk. CVD was one of the five principal causes of death in Malaysia in 2019 [3]. Accessing and utilizing health information interventions should be age friendly where individuals of different age categories can obtain information easily. Increasing the level of health literacy to adopt healthy eating practices among Malaysians should be the focus of the government, in an attempt to reduce CVD risk. Comparison of calories and fat and sodium content of home-cooked and outside meals should be included in health education mate- rials to promote healthy eating at home. Besides the major ethnic groups, public health interventions should also focus on minority communities. It is essential to raise the public's awareness of healthy diets and lifestyle to reduce the rate of mortality due to CVDs.

\section{Data Availability}

Data requestors will need to fill in an online application form from the SEACO website (https://www.monash.edu.my/ seaco/research-and-training/how-to-collaborate-with-seaco). All the application will go through the SEACO Review Committee.

\section{Conflicts of Interest}

The authors declare no conflict of interest.

\section{Acknowledgments}

The authors would like to express their appreciation to the SEACO Field Team and data operation unit. We would like to thank Professor Dr. Tin Tin Su from Monash University Malaysia who conceptualized and planned the study, Ms. Chiew Way Ang who analysed and interpreted the result and drafted the manuscript, Mr. Roshidi Ismail who proofread and drafted the manuscript, and all authors who provided critical feedback and helped shape the research analysis and final manuscript. The South East Asia Community Observatory (SEACO) was supported by Monash University Clayton and Malaysia campuses and the Jeffrey Cheah School of Medicine and Health Sciences. Ms. Chiew Way Ang was partly funded by the ASEAN Grant (ASE000011) during the analysis and writing of this paper. The Article Processing Charge (APC) was partly supported by Jeffrey Cheah School of Medicine and Health Sciences.

\section{References}

[1] World Health Organization, Cardiovascular diseases, 2017, https://www.who.int/news-room/fact-sheets/detail/ cardiovascular-diseases-(cvds).

[2] Institute for Public Health, Non-communicable Diseases, Risk Factors \& Other Health Problems, Institute for Public Health, Kuala Lumpur, Malaysia, 2015, https://www.moh.gov.my/ moh/resources/nhmsreport2015vol2.pdf.

[3] Department of Statistics Malaysia, Statistics on causes of death, Malaysia, 2019, 2019, https://dosm.gov.my/v1/ i n d e x.ph p ? r = c ol u m n / p d f P r e v \& i d = RUxlSDNkcnRVazJnakNCNVN2VGgrdz09.

[4] Ministry of Health, National Plan of Action for Nutrition of Malaysia III 2016-2025, Ministry of Health, Malaysia, 2016, http://nutrition.moh.gov.my/wp-content/uploads/2016/12/ NPANM_III.pdf.

[5] B. Borhanuddin, A. Mohd Nawi, S. A. Shah et al., "10-year cardiovascular disease risk estimation based on lipid profile-based and BMI-based Framingham risk scores across multiple sociodemographic characteristics: the Malaysian cohort project," The Scientific World Journal, vol. 2018, Article ID 2979206, 8 pages, 2018. 
[6] C. Y. Chin and S. Pengal, "Cardiovascular disease risk in a semirural community in Malaysia," Asia Pacific Journal of Public Health, vol. 21, no. 4, pp. 410-420, 2009.

[7] B. Jin, X. Bai, L. Han, J. Liu, W. Zhang, and X. Chen, “Association between kidney function and Framingham global cardiovascular disease risk score: a Chinese longitudinal study," PLoS One, vol. 9, no. 1, article e86082, 2014.

[8] S. Selvarajah, G. Kaur, J. Haniff et al., "Comparison of the Framingham risk score, SCORE and WHO/ISH cardiovascular risk prediction models in an Asian population," Internation Journal of Cardiology, vol. 176, no. 1, pp. 211-218, 2014.

[9] T. T. Su, M. Amiri, F. Mohd Hairi, N. Thangiah, A. Bulgiba, and H. A. Majid, "Prediction of cardiovascular disease risk among low-income urban dwellers in metropolitan Kuala Lumpur, Malaysia," BioMed Research International, vol. 2015, Article ID 516984, 8 pages, 2015.

[10] G. T. C. Ko, J. C. N. Chan, S. D. Y. Tong et al., "Associations between dietary habits and risk factors for cardiovascular diseases in a Hong Kong Chinese working population-the" Better Health for Better Hong Kong"(BHBHK) health promotion campaign," Asia Pacific Journal of Clinical Nutrition, vol. 16, no. 4, pp. 757-765, 2007.

[11] N. H. Ismail, N. M. Rosli, D. Mahat, K. H. Yusof, and R. Ismail, "Cardiovascular risk assessment between urban and rural population in Malaysia," Medical Journal of Malaysia, vol. 71, no. 6, pp. 331-337, 2016.

[12] Y. Mamani-Ortiz, M. San Sebastian, A. X. Armaza et al., "Prevalence and determinants of cardiovascular disease risk factors using the WHO STEPS approach in Cochabamba Bolivia," BMC Public Health, vol. 19, no. 1, p. 786, 2019.

[13] I. Aniza, A. Nurmawati, Y. Hanizah, and T. J. Ahmad, "Modifiable risk factors of cardiovascular disease among adults in rural community of Malaysia: a cross sectional study," Malaysian Journal of Public Health Medicine, vol. 16, no. 1, pp. 5361, 2016.

[14] S. M. Ghazali, Z. Seman, K. C. Cheong et al., "Sociodemographic factors associated with multiple cardiovascular risk factors among Malaysian adults," BMC Public Health, vol. 15 , no. 1, p. $68,2015$.

[15] W. M. Schultz, H. M. Kelli, J. C. Lisko et al., "Socioeconomic status and cardiovascular outcomes: challenges and interventions," Circulation, vol. 137, no. 20, pp. 2166-2178, 2018.

[16] U. Partap, E. H. Young, P. Allotey et al., "HDSS profile: the South East Asia community observatory health and demographic surveillance system (SEACO HDSS)," International Journal of Epidemiology, vol. 46, no. 5, pp. 1370-1371g, 2017.

[17] R. B. D'Agostino Sr., R. S. Vasan, M. J. Pencina et al., "General cardiovascular risk profile for use in primary care: the Framingham heart study," Circulation, vol. 117, no. 6, pp. 743753, 2008.

[18] World Health Organization, WHO STEPS Surveillance Manual: The WHO STEPwise Approach to Chronic Disease Risk Factor Surveillance, World Health Organization, Switzerland, 2005, https://www.who.int/ncds/surveillance/steps/STEPS_ Manual.pdf.

[19] M. E. Lacruz, A. Kluttig, O. Kuss et al., "Short-term blood pressure variability - variation between arm side, body position and successive measurements: a population-based cohort study," BMC Cardiovascular Disorders, vol. 17, no. 1, p. 31, 2017.
[20] K. K. Ng and Y. C. Chia, "Utility of Framingham's model in predicting coronary heart disease risk in Malaysia, a developing country," Atherosclerosis, vol. 1, no. 9, p. 92, 2008.

[21] K. Friis, M. Lasgaard, G. Rowlands, R. H. Osborne, and H. T. Maindal, "Health literacy mediates the relationship between educational attainment and health behavior: a Danish population-based study," Journal of Health Communication, vol. 21, supplement 2, pp. 54-60, 2016.

[22] I. van der Heide, J. Wang, M. Droomers, P. Spreeuwenberg, J. Rademakers, and E. Uiters, "The relationship between health, education, and health literacy: results from the Dutch adult literacy and life skills survey," Journal of Health Communication, vol. 18, pp. 172-184, 2013.

[23] C. Lachat, E. Nago, R. Verstraeten, D. Roberfroid, J. Van Camp, and P. Kolsteren, "Eating out of home and its association with dietary intake: a systematic review of the evidence," Obesity Review, vol. 13, no. 4, pp. 329-346, 2012.

[24] E. Llanaj, R. Adany, C. Lachat, and M. D'Haese, "Examining food intake and eating out of home patterns among university students," PLoS One, vol. 13, no. 10, article e0197874, 2018.

[25] World Health Organization, Global Physical Activity Questionnaire (GPAQ), World Health Organization, Switzerland, 2005, https://www.who.int/ncds/surveillance/steps/GPAQ\% 20Instrument\%20and\%20Analysis\%20Guide\%20v2.pdf.

[26] M. H. Ahmad, N. Nishi, M. F. Mohd Yusoff, and T. Aris, "Cardiovascular disease risk and its association with body mass index in Malaysians based on the World Health Organization/International Society of Hypertension risk prediction chart," Health Science Journal, vol. 12, no. 1, p. 550, 2018.

[27] M. Amiri, H. A. Majid, F. Hairi, N. Thangiah, A. Bulgiba, and T. T. Su, "Prevalence and determinants of cardiovascular disease risk factors among the residents of urban community housing projects in Malaysia," BMC Public Health, vol. 14, no. 3, 2014.

[28] N. T. Amplavanar, K. Gurpreet, M. S. Salmiah, and N. Odhayakumar, "Prevalence of cardiovascular disease risk factors among attendees of the Batu 9, Cheras Health Centre, Selangor, Malaysia," Medical Journal of Malaysia, vol. 65, no. 3, pp. 166-172, 2010.

[29] N. M. Z. Mohd Azahar, A. D. S. Krishnapillai, N. H. Zaini, and K. Yusoff, "Risk perception of cardiovascular diseases among individuals with hypertension in rural Malaysia," Heart Asia, vol. 9, article e010864, 2017.

[30] A. Rosengren, A. Smyth, S. Rangarajan et al., "Socioeconomic status and risk of cardiovascular disease in 20 low-income, middle-income, and high-income countries: the prospective urban rural epidemiologic (PURE) study," The Lancet Global Health, vol. 7, no. 6, pp. e748-e760, 2019.

[31] D. A. Bennett, H. Du, R. Clarke et al., “Association of physical activity with risk of major cardiovascular diseases in Chinese men and women," JAMA Cardiology, vol. 2, no. 12, pp. 1349-1358, 2017.

[32] K. Francis, "Physical activity in the prevention of cardiovascular disease," Physical Therapy, vol. 76, no. 5, pp. 456-468, 1996.

[33] N. Lillo, G. Palomo-Vélez, E. Fuentes, and I. Palomo, "Role of physical activity in cardiovascular disease prevention in older adults," Sport Sciences for Health, vol. 11, no. 3, pp. 227-233, 2015.

[34] K. Srinath Reddy and M. B. Katan, "Diet, nutrition and the prevention of hypertension and cardiovascular diseases," $\mathrm{Pub}$ lic Health Nutrition, vol. 7, no. 1A, pp. 167-186, 2004. 
[35] E. Yu, V. S. Malik, and F. B. Hu, "Cardiovascular disease prevention by diet modification: JACC health promotion series," Journal of the American College of Cardiology, vol. 72, no. 8, pp. 914-926, 2018.

[36] T. Yang, C. A. Sun, Y. C. Chou et al., "Gender differences in obesity indices in a 10-year risk for cardiovascular disease," British Journal of Medicine and Medical Research, vol. 5, no. 9, pp. 1121-1130, 2015.

[37] R. Yadav, R. K. Yadav, K. Sarvottam, and R. Netam, "Framingham risk score and estimated 10-year cardiovascular disease risk reduction by a short-term yoga-based lifestyle intervention," The Journal of Alternative and Complement Medicine, vol. 23, no. 9, pp. 730-737, 2017.

[38] O. A. Babatunde, S. O. Olarewaju, A. A. Adeomi et al., "10-year risk for cardiovascular diseases using WHO prediction chart: findings from the civil servants in South-Western Nigeria," BMC Cardiovascular Disorders, vol. 20, no. 1, p. 154, 2020.

[39] S. Boo and E. S. Froelicher, "Cardiovascular risk factors and 10 -year risk for coronary heart disease in Korean women," Asian Nursing Research, vol. 6, no. 1, pp. 1-8, 2012.

[40] N. B. M. Kasim, M. H. B. Ahmad, A. B. B. Shaharudin, B. M. Naidu, C. Y. Ying, and H. T. B. Aris, "Food choices among Malaysian adults: findings from Malaysian Adults Nutrition Survey (MANS) 2003 and MANS 2014," Malaysian Journal of Nutrition, vol. 24, no. 1, pp. 63-75, 2018.

[41] Department of Statistics Malaysia, Household Expenditure Survey Report 2019, Department of Statistics, Malaysia, 2020.

[42] S. Brandhorst and V. D. Longo, "Dietary restrictions and nutrition in the prevention and treatment of cardiovascular disease," Circulation Research., vol. 124, no. 6, pp. 952-965, 2019.

[43] S. S. Anand, C. Hawkes, R. J. de Souza et al., "Food consumption and its impact on cardiovascular disease: importance of solutions focused on the globalized food system: a report from the workshop convened by the World Heart Federation," Journal of the American College of Cardiology., vol. 66, no. 14, pp. 1590-1614, 2015.

[44] C. C. Kee, Y. L. Cheong, K. H. Lim et al., "Association between availability of neighborhood fast food outlets and overweight among 5-18 year-old children in peninsular Malaysia: a cross-sectional study," International Journal of Environmental Research and Public Health, vol. 16, no. 4, p. 593, 2019.

[45] R. K. Vijayakumaran and A. S. Nur, "Influences of nutrition information on fast food consumption among undergraduates," Food Research, vol. 2, no. 3, pp. 228-233, 2018.

[46] N. N. Abdullah, M. M. Mokhtar, M. H. Abu Bakar, and W. Al-Kubaisy, "Trend on fast food consumption in relation to obesity among Selangor urban community," Procedia-Social and Behavioral Sciences., vol. 202, pp. 505-513, 2015.

[47] N. Ali and M. A. Abdullah, "The food consumption and eating behaviour of Malaysian urbanites: issues and concerns," Geografia-Malaysian Journal of Society and Space, vol. 8, no. 6, pp. 157-165, 2017.

[48] T. Fournier, L. Tibere, C. Laporte et al., "Eating patterns and prevalence of obesity. Lessons learned from the Malaysian food barometer," Appetite, vol. 107, pp. 362-371, 2016.

[49] R. M. Yunus, M. S. A. Saman, A. Zubillah et al., "Health literacy among urban Malaysian elders: a descriptive study," ASM Science Journal, vol. 13, pp. 7-12, 2020.
[50] S. R. A. Hamzah, T. Suandi, and N. H. Ishak, "Association between health literacy and demographic factors among adolescents in Malaysia," Age, vol. 15, no. 19, pp. 3-8, 2016.

[51] Ministry of Health, PeKa B40 Report 2019-2020, Protect Health Corporation, Malaysia, 2019, https://protecthealth .com.my/wp-content/uploads/2021/10/PeKaB40_Report_ 2019-2020.pdf. 